\title{
PERANCANGAN SISTEM PENGOLAHAN LIMBAH CAIR KAWASAN PASAR ANGGREK KOTA PONTIANAK
}

Astari Dwi Putri ${ }^{(1)}$, Isna Apriani ${ }^{1)}$, Winardi Yusuf ${ }^{(1)}$

${ }^{1}$ Program Studi Teknik Lingkungan, Universitas Tanjungpura, Pontianak

Email : astaridwi69@gmail.com

\begin{abstract}
ABSTRAK
Perancangan sistem pengolahan limbah cair pada sebuah pasar diperlukan untuk memperbaiki kualitas air yang akan dibuang sehingga tidak mencemari lingkungan. Studi kasus pada skripsi ini adalah Pasar Anggrek Kota Pontianak yang terletak di pertigaan Jalan Ya'M Sabran dan Jalan Sultan Hamid Pontianak Timur. Pasar Anggrek ini belum beroperasi dan belum memiliki sebuah IPAL. Perancangan ini menggunakan pengolahan secara fisik dan biologis. Sistem pengolahan biologi yang digunakan adalah biofilter anerob aerob terpisah dengan proses pengolahan yang meliputi, bak screen, bak ekualisasi,bak pengendap pertama, biofilter anerob, biofilter aerob, bak pengendap akhir. Dalam hal ini limbah cair pasar masuk dalam kategori limbah cair domestik. Tahap perancangan IPAL Pasar Anggrek Kota Pontianak meliputi pengambilan sampel air limbah Pasar Flamboyan, menghitung debit limbah cair, menentukan metode pengolahan limbah cair Pasar Anggrek Kota Pontianak, merencanakan IPAL, menghitung anggaran biaya. Debit air limbah yang dihasilkan diperkirakan sebesar $1,44 \mathrm{~m}^{3}$ /hari dengan konsentrasi limbah $\mathrm{pH} 6,19$, BOD 1.264,8 mg/l, TSS 9.729 mg/l, minyak dan lemak 0,025 mg/l. Instalasi Pengolahan Air Limbah Pasar Anggrek ini memiliki 5 kompartemen yaitu Bar Screen yang memiliki volume $0,24 \mathrm{~m}^{3} /$ hari,bak ekualisasi memiliki volume $0,24 \mathrm{~m}^{3} /$ hari, bak pengendap pertama memiliki volume $0,18 \mathrm{~m}^{3}$, biofilter anaerob memiliki volume $0,73 \mathrm{~m}^{3}$, biofilter anaerob-aerob memiliki volume $0,25 \mathrm{~m}^{3}$, dan bak pengendap akhir memiliki volume $0,25 \mathrm{~m}^{3}$. Biaya anggaran biaya yang akan dibutuhkan untuk merancang IPAL di Pasar Anggrek Kota POontianak sebesar Rp. Rp. 26.955.500,00,- ( Dua Puluh Enam Juta Sembilan Ratus Lima Puluh Lima Ribu Lima Ratus Rupiah ).
\end{abstract}

Kata kunci : Biofilter, IPAL pasar, pengolahan limbah pasar, karakteristik limbah cair pasar

\section{ABSTRACT}

The design of wastewater treatment systems in a market is to improve the quality of water to be discharged so is not pollute the environment. The case in this thesis is Pasar Anggrek Pontianak City which is located at the junction of Ya'M Sabran Street and Sultan Hamid Street, East Pontianak. Pasar Anggrek has not been in operation and don't had a WWTP. This design uses the physical and biological processing. Biological treatment system used is the anaerobic aerobic biofilter separately by processing that includes, like a screen, equalization, first sedimentation basin, anaerobic biofilter, biofilter aerobic, final sedimentation basin. WWTP design stage Pasar Anggrek Pontianak City include waste water sampling Pasar Flamboyan, calculate discharge wastewater, wastewater treatment method determines Pasar Anggrek Pontianak, planned WWTP, calculated the budget. Discharge of waste water produced is estimated at $1.44 \mathrm{m3} /$ day of wastewater with a concentration of $6.19 \mathrm{pH}, B O D 1264.8 \mathrm{mg} / \mathrm{l}$, TSS $9729 \mathrm{mg} / \mathrm{l}$, oils and fats $0,025 \mathrm{mg} / \mathrm{l}$. Pasar Anggrek Wastewater Treatment has five compartments that Bar Screen which has a volume 0,24m3 / day, equalization basin has a volume 0,24m3 / day, the first sedimentation basin has a volume of $0.18 \mathrm{m3}$, anaerobic biofilter has a volume $0,73 \mathrm{~m} 3$, anaerobic-aerobic biofilter has a volume $0,25 \mathrm{~m} 3$, and final sedimentation basin has a volume $0,25 \mathrm{~m} 3$. The cost of the budget that will be needed to design the WWTP at Pasar Anggrek, Pontianak City Rp. 26,955,500.00, - (Twenty-Six Million Nine Hundred Fifty Five Thousand Five Hundred Rupiah).

Key Word: Biofilter, WWTP, Sewage treatment market, Characteristics of liquid waste market 


\section{PENDAHULUAN}

Kota Pontianak sebagai Ibu Kota Provinsi Kalimantan Barat merupakan sebuah kota yang berkembang. Perkembangan kota Pontianak ditandai oleh kemajuan pembangunan, dan sangat dipengaruhi oleh berbagai aktivitas di segala sektor,terutama oleh kegiatan sektor jasa perdagangan, dan pemerintahan. Selain sebagai berbagai aktivitas, maka secara tidak langsung kota Pontianak juga merupakan pusat dari berbagai masalah kesehatan lingkungan. Salah satu masalah kesehatan lingkungan yang dapat terjadi di masyarakat dikarenakan kurangnya penanganan sampah dan limbah cair yang dihasilkan dari berbagai aktifitas di Kota Pontianak. Sumber limbah cair dapat berasal dari kawasan domestik misalnya pasar, perumahan, perkantoran, restoran dan lain-lain. Pasar mempunyai potensi yang cukup besar untuk menimbulkan sampah dan limbah cair. Sementara pengolahan limbah cair merupakan permasalahan tersendiri yang dihadapi suatu kota besar.

Pasar di Kota Pontianak belum memiliki sistem pengolahan air limbah. Dengan demikian air limbah tersebut dapat mengakibatkan tercemarnya badan sungai, sehingga badan sungai yang diperuntukkan sebagai bahan baku air minum dan MCK menjadi tercemar. Agar dapat mengolah limbah cair pasar dengan benar, maka langkah awal perlu diketahui adalah pemahaman terhadap kuantitas, wujud, karakteristik dan potensi dari limbah cair yang akan diolah. Dalam hal ini limbah cair pasar masuk dalam kategori limbah cair domestik. Baku mutu air limbah domestik untuk limbah cair pasar yang telah diatur dalam keputusan Menteri Lingkungan Hidup No.112 Tahun 2003 adalah untuk parameter pH, BOD, TSS, minyak dan lemak (Soeparman 2006). Perancangan sistem pengolahan limbah cair pada sebuah pasar diperlukan untuk memperbaiki kualitas air yang akan dibuang sehingga tidak mencemari lingkungan atau daerah tersebut. Studi kasus pada skripsi ini adalah Pasar Anggrek Kota Pontianak yang terletak di pertigaan Jalan Ya'M Sabran dan Jalan Sultan Hamid Pontianak Timur.

\section{METODE PENELITIAN}

\section{A. Lokasi Dan Waktu Perancangan}

Lokasi studi perancangan berada di Jalan Ya'm Sabran Kecamatan Pontianak Timur, Kota Pontianak. Perancangan ini dilaksanakan selama kurang lebih 1 Tahun yang dimulai pada bulan Mei 2014 dan berakhir pada Mei 2015.

\section{B. Jenis Data}

\section{- Data Primer}

- Data primer yang dibutuhkan pada perancangan ini yaitu parameter kualitas air limbah cair yang berasal dari Pasar Flamboyan, khususnya pasar basah yang mana aktivitasnya sama dengan aktivitas yang akan terdapat pada Pasar Anggrek. Berdasarkan Keputusan Menteri Lingkungan Hidup No.112 Tahun 2003, parameter yang akan diuji adalah pH, BOD, TSS, Minyak dan Lemak.

- Data sekunder yang dibutuhkan pada perancangan ini yaitu :

- Gambaran umum Pasar Anggrek Pontianak

- Denah Pasar Anggrek

- Layout Pasar Anggrek

- Jumlah kios

- Kebutuhan air bersih dan debit limbah cair

\section{Tahap Perancangan}

- Pengambilan sampel limbah cair pasar Pasar Flamboyan

Pengambilan sampel air limbah Pasar Flamboyan dilakukan pada hari senin pada pukul 13.00 WIB. Dengan asumsi bahwa tidak terdapat perbedaan beban organik air limbah yang signifikan setiap harinya, maka asumsi beban organik sama dengan 
setiap harinya dimana pemilihan hari sampling tidak mempengaruhi nilai kualitas air limbah selama pasar masih beroperasi.

- Perhitungan debit limbah cair

Perhitungan debit air limbah didasarkan pada jumlah limbah cair yang dihasilkan oleh para pedagang di Pasar Anggrek. Oleh karena itu Pasar Anggrek ini belum beropersi, maka dapat diasumsikan debit limbah yang dihasilkan pedagang Pasar Anggrek sebesar 36 liter/hari/kios.

Sehingga diperoleh debit air limbah untuk perancangan IPAL adalah :

$\mathrm{Q}=$ banyaknya kios $\mathrm{x}$ produksi air limbah/kios/hari

$=40 \mathrm{kios} \times 36$ liter $/ \mathrm{kios} /$ hari

$=1.440$ liter $/$ hari

$=1,44 \mathrm{~m}^{3} /$ hari

- Penentuan metode pengolahan limbah cair Pasar Anggrek dilihat berdasarkan kualitas dan kuantitas air limbah

Setelah hasil dari laboratorium selesai, hasil data tersebut di bandingkan dengan baku mutu air limbah domestik. Dengan demikian baru bisa menentukan metode pengolahan apa yang tepat berdasarkan hasil kualitas dan kuantitas limbah cair pasar tersebut.

- Merencanakan IPAL

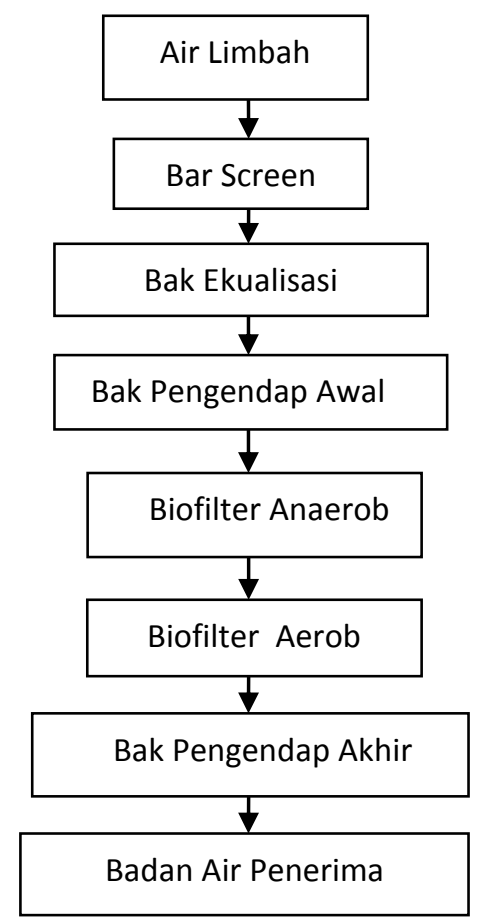

Gambar 1 Diagram Alir Pengolahan Limbah

- Menghitung Rencana Anggaran Biaya

Rencana Anggaran Biaya ini berisikan tentang hasil perhitungan harga satuan untuk pembuatan bangunan instalasi pengolahan. 


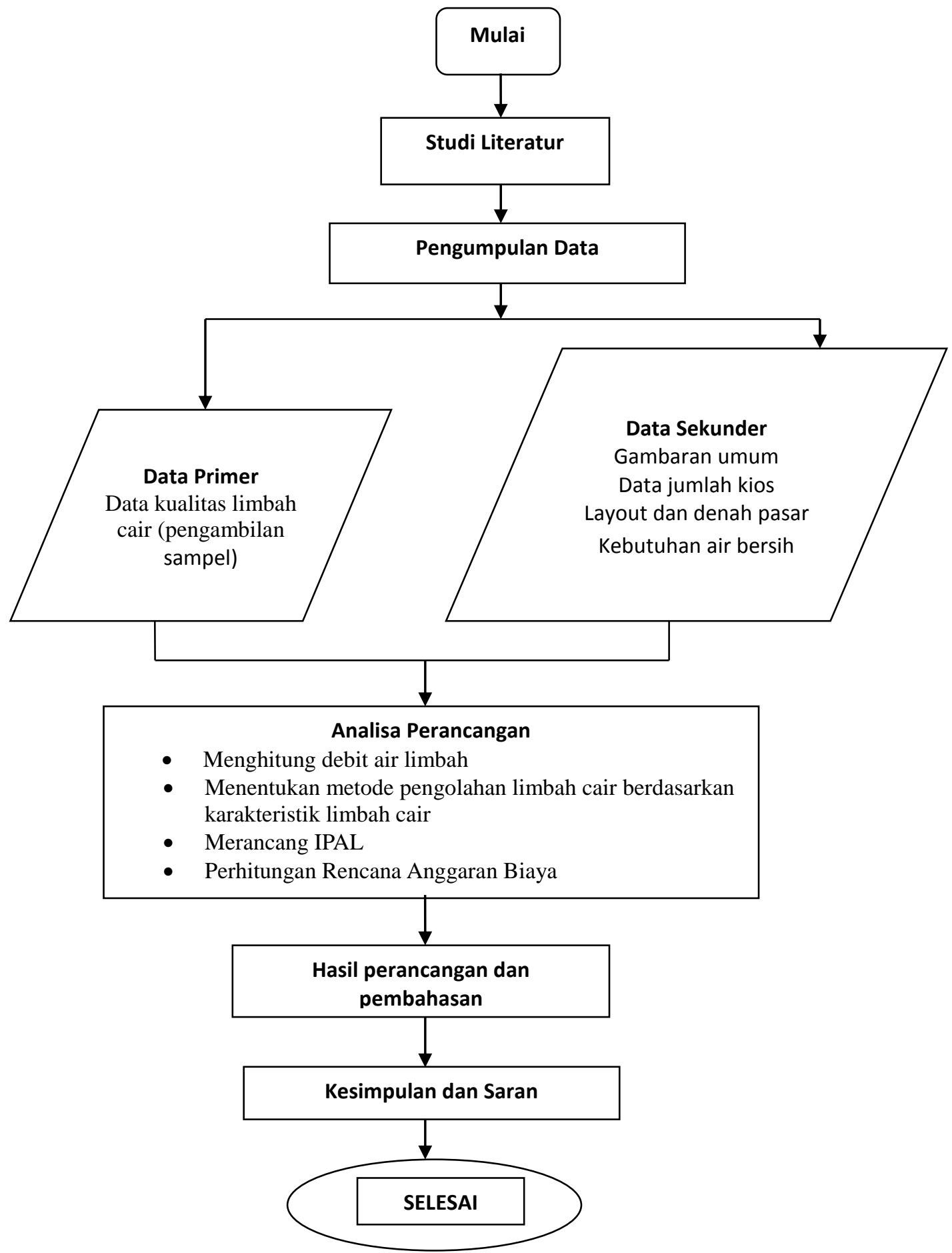

Gambar 2 Diagram Alir Perancangan

\section{ANALISIS DAN PERHITUNGAN PERANCANGAN}

Perancangan instalasi pengolahan air limbah terdapat beberapa faktor yang perlu diperhatikan sebagai dasar perancangan dan menjadi penentu dalam pemilihan proses pengolahan. Faktor-faktor ini diantaranya adalah debit/kuantitas air buangan, dan karakteristik/kualitas air buangan. 


\section{A. Analisis Debit Air Limbah}

Debit air limbah dibutuhkan untuk menentukan kapasitas pengolahan. Perhitungan debit air limbah didasarkan pada jumlah limbah cair yang dihasilkan oleh para pedagang di Pasar Anggrek. Menurut peraturan Gubernur Provinsi Jakarta No. 122 tahun 2005 debit limbah cair yang dihasilkan sebesar 36 liter/hari/kios. Setelah mendapatkan jumlah limbah cair tersebut maka dapat dihitung debit limbah cair yang dihasilkan dari Pasar Anggrek sebagai berikut :

$$
\begin{aligned}
\text { Debit limbah } & =36 \text { liter/hari/kios } \times 40 \text { kios } \\
& =1.440 \text { liter/hari } \\
& =1,44 \mathrm{~m}^{3} / \text { hari }
\end{aligned}
$$

\section{B. Analisa Karakteristik Air Limbah}

Analisa karakteristik air limbah dilakukan untuk mengetahui sifat dan karakteristik dari air limbah di Pasar Anggrek. Analisa karakteristik ini dilakukan berdasarkan Keputusan Menteri Negara Lingkungan Hidup Nomor 112 Tahun 2003 tentang Baku Mutu Air Limbah Domestik, yaitu terhadap parameter BOD, TSS, pH, minyak dan lemak. Berikut ini adalah hasil dari uji pengambilan sampel air limbah Pasar Flamboyan dapat dilihat pada Tabel 1 berikut

Tabel 1 Karakteristik Air Limbah Pasar Flamboyan

\begin{tabular}{|c|c|c|c|}
\hline Parameter & Satuan & Kadar & Baku Mutu \\
\hline BOD & $\mathrm{mg} / 1$ & 1264,8 & 100 \\
\hline TSS & $\mathrm{mg} / 1$ & 9729 & 100 \\
\hline $\begin{array}{c}\text { Minyak dan } \\
\text { Lemak }\end{array}$ & $\mathbf{m g} / \mathbf{l}$ & $\mathbf{0 , 0 2 5}$ & $\mathbf{1 0}$ \\
\hline $\mathbf{p H}$ & - & $\mathbf{6 , 1 9}$ & $\mathbf{6 - 1 0}$ \\
\hline
\end{tabular}

Berdasarkan hasil yang terdapat pada diketahui bahwa parameter BOD dan TSS melebihi baku mutu yang diperbolehkan. Parameter BOD dari limbah Pasar Anggrek sebesar 1264,80 mg/L sedangkan baku mutu yang diperbolehkan Keputusan Menteri Negara Lingkungan Hidup Nomor 112 Tahun 2003 tentang Baku Mutu Air Limbah Domestik hanya sebesar $100 \mathrm{mg} / \mathrm{L}$. Demikian juga pada parameter TSS yaitu sebesar $9729,00 \mathrm{mg} / \mathrm{L}$ sedangkan baku mutu yang diperbolehkan hanya sebesar $100 \mathrm{mg} / \mathrm{L}$. Berikut adalah konversi beban BOD dan TSS per hari:

Diketahui : Kadar TSS

$$
\text { Debit Air Limbah Pasar Anggrek }
$$

$$
\begin{aligned}
& =9729,00 \mathrm{mg} / \mathrm{L} \\
& =1.440 \mathrm{~L} / \text { hari }
\end{aligned}
$$

Maka didapatkan beban TSS per hari sebagai berikut:

Beban TSS : 9729 mg/l x 1.440 liter/hari

$$
\begin{aligned}
& =14.000 .000 \mathrm{mg} / \text { hari } \\
& =14 \mathrm{~kg} / \text { hari }
\end{aligned}
$$

Diketahui : Kadar BOD

Debit Air Limbah Pasar Anggrek

$$
=1264,80 \mathrm{mg} / \mathrm{L}
$$

$$
=1.440 \mathrm{~L} / \text { hari }
$$

Maka didapatkan beban BOD per hari sebagai berikut: Beban BOD : 1264,80 mg/l x 1.440 liter/hari

$$
\begin{aligned}
& =1.821 .312 \mathrm{mg} / \text { hari } \\
& =1,83 \mathrm{~kg} / \text { hari }
\end{aligned}
$$

Parameter minyak dan lemak serta $\mathrm{pH}$ air limbah tidak diperhitungkan dalam perencanaan ini karena kedua parameter tersebut berada di bawah baku mutu air limbah yang diperbolehkan. Sehingga tidak perlu unit pengolahan khusus dan IPAL yang akan di rencanakan menggunakan aliran gravitasi sehingga tidak memerlukan pompa. Berdasarkan data jumlah produksi air limbah yang dihasilkan oleh Pasar Anggrek, maka diketahui kapasitas desain dalam perancangan ini sebagai berikut :
- Kapasitas Pengolahan
$: 1,44 \mathrm{~m}^{3} /$ hari 


$\begin{array}{lll} & : 0,06 \mathrm{~m}^{3} / \mathrm{jam} \\ \circ & \text { BOD Air Limbah Rata-Rata } & : 1264,80 \mathrm{mg} / \text { liter } \\ \circ & \text { Beban BOD } & : 1,83 \mathrm{~kg} / \mathrm{hari} \\ \circ & \text { TSS Air Limbah Rata-Rata } & : 9729 \mathrm{mg} / \mathrm{liter} \\ \circ & \text { Beban TSS } & : 14 \mathrm{~kg} / \mathrm{hari}\end{array}$

C. Perhitungan Perancangan IPAL

- Bar Screen

\begin{tabular}{|c|c|}
\hline $\mathrm{L}$ & $=n \times \omega+(n+1) b$ \\
\hline $1 \mathrm{~m}$ & $=n \times 0,008 m+(n+1) 0,025 m$ \\
\hline $1 \mathrm{~m}$ & $=0,008 n+0,025 n+0,025 m$ \\
\hline $1 m-0,025 m$ & $=0,008 n+0,025 n$ \\
\hline $0,975 \mathrm{~m}$ & $=0,033 n$ \\
\hline$n$ & $=29,54$ \\
\hline & $=30$ buah \\
\hline
\end{tabular}

Jumlah celah $(\mathrm{N})$

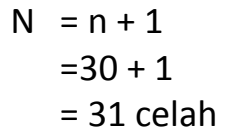

Lebar bukaan bar dalam keadaan bersih (Ls)

$\mathrm{Ls}=\mathrm{N} \times \mathrm{b}$

$=31 \times 0,025 \mathrm{~m}$

$=0,775 \mathrm{~m} \approx 0,8$

Panjang batang bar yang terendam

$$
\begin{aligned}
& =\frac{D}{\operatorname{Sin} 60^{\circ}} \\
& =\frac{0,25 \mathrm{~m}}{0,86} \\
& =0,288 \mathrm{~m}
\end{aligned}
$$

Kecepatan melalui screen

$$
\begin{aligned}
=\frac{\mathrm{Q}}{\text { Ls } x \text { Panjang batang bar yang terendam }} \\
=\frac{1,44 \mathrm{~m}^{3} / \text { hari }}{0,8 \mathrm{~m}^{3} \times 0,288 \mathrm{~m}} \\
=\frac{1,44 / \text { hari }}{0,230} \\
=\frac{6,26 \mathrm{~m} / \mathrm{hari}}{86,400 \mathrm{~m}} \\
=0,00072 \mathrm{~m} / \mathrm{s}
\end{aligned}
$$

- Bak Ekualisasi

$\mathrm{V}=\mathrm{Q} \times \mathrm{td}$

$V=\frac{4}{24}$ hari $\times 1,44 \mathrm{~m}^{3} /$ hari

$\mathrm{V}=0,24 \mathrm{~m}^{3} /$ hari

Jika kedalaman bak direncanakan 0,5 meter, maka luas bak penampung $\mathrm{h}=1 \mathrm{~m}$

$$
\begin{aligned}
A & =\frac{\text { volume }}{\text { tinggi }} \\
& =\frac{0,24 \mathrm{~m} 3 / \text { hari }}{0,5 \mathrm{~m}}=0,48 \mathrm{~m}^{3}
\end{aligned}
$$

Jika lebar direncanakan 1 meter maka panjang bak penampung 


$$
\begin{aligned}
\text { Panjang } & =\frac{A}{l} \\
& =\frac{0,24 \mathrm{~m}^{3}}{1 \mathrm{~m}} \\
& =0,48 \mathrm{~m} \approx 0,5 \mathrm{~m}
\end{aligned}
$$

Sehingga dimensi bak equalisasi adalah

Lebar

$$
=0,5 \mathrm{~m}
$$

Tinggi

$$
=1 \mathrm{~m}
$$

Freeboard

$$
=0,1 \mathrm{~m}
$$

- Bak Pengendap Pertama

Ditetapkan waktu tinggal sebesar 3 jam

$\mathrm{V}=\frac{3}{24}$ hari $\times 1,44 \mathrm{~m}^{3} /$ hari

$$
=0,18 \mathrm{~m}^{3}
$$

jika tinggi bak direncanakan 0,5 meter, maka luas bak pengendap adalah

$$
\begin{aligned}
A & =\frac{\text { volume }}{\text { ting } i} \\
& =\frac{0,18 \mathrm{~m}^{3}}{0,5 \mathrm{~m}}=0,36 \mathrm{~m}^{3}
\end{aligned}
$$

jika lebar bak pengendap direncanakan 1 meter maka panjang bak pengendap adalah

$\mathrm{L}=\frac{\mathrm{A}}{h}$

$$
\begin{aligned}
& =\frac{0,36 \mathrm{~m}^{3}}{1 \mathrm{~m}} \\
& =0,36 \mathrm{~m}^{2} \approx 0,4 \mathrm{~m}^{3}
\end{aligned}
$$

Sehingga dimensi bak pengendap pertama adalah

$\begin{array}{ll}\text { P } & =0,4 \mathrm{~m} \\ \text { Lebar } & =1 \mathrm{~m} \\ \text { Tinggi } & =0,5 \mathrm{~m} \\ \text { Freeboard } & =0,1 \mathrm{~m}\end{array}$

\section{- Bak Biofilter Anareob}

Jika direncanakan waktu tinggal sebesar 7,3 jam, maka diketahui volume cek nya sebagai berikut :

$$
\begin{aligned}
V & =\frac{7,3}{24} \text { hari } \times 1,44 \mathrm{~m}^{3} / \text { hari } \\
& =0,44 \mathrm{~m}^{3}
\end{aligned}
$$

jika tinggi bak direncanakan $1 \mathrm{~m}$, maka luas bak reaktor adalah

$$
\begin{aligned}
A= & \frac{\text { volume }}{\text { tinggi }} \\
& =\frac{0,44 \mathrm{~m}^{3}}{1 \mathrm{~m}}=0,44 \mathrm{~m}^{3}
\end{aligned}
$$

jika lebar bak pengendap direncanakan 0,5 m maka panjang bak pengendap adalah

$$
\mathrm{L}=\frac{\mathrm{A}}{\mathrm{L}}
$$

$$
=\frac{0,44 \mathrm{~m}^{3}}{0,5 \mathrm{~m}}=1
$$

Maka ditetapkan reaktor anaerob:

$\begin{array}{ll}\text { Panjang } & =1 \mathrm{~m} \\ \text { Lebar } & =1 \mathrm{~m} \\ \text { tinggi } & =0,5 \mathrm{~m} \\ \text { Freeboard } & =0,1 \mathrm{~m}\end{array}$


Vefektif $\quad=0,5 \mathrm{~m}^{3}$

- Biofilter Aerob

BOD yang disisihkan = Effisiensi $x$ beban BOD di dalam air limbah

$$
\begin{aligned}
& =60 \% \times 0,131 \mathrm{~kg} / \text { hari } \\
& =0,078 \mathrm{~kg} / \text { hari }
\end{aligned}
$$

Ditetapkan waktu tinggal sebesar 4 jam

$\mathrm{V}=\frac{2,6}{24}$ hari $\times 1,44 \mathrm{~m}^{3} /$ hari

$=0,16 \mathrm{~m}^{3}$

jika tinggi bak direncanakan $1 \mathrm{~m}$, maka luas bak pengendap adalah

$$
\begin{aligned}
A & =\frac{\text { volume }}{\text { tinggi }} \\
& =\frac{0,16 \mathrm{~m}^{3}}{1 \mathrm{~m}}=0,156 \mathrm{~m}^{3}
\end{aligned}
$$

jika lebar bak pengendap direncanakan 0,5 m maka panjang bak pengendap adalah $\mathrm{L}=\frac{\mathrm{A}}{\mathrm{L}}$

$=\frac{0,16 \mathrm{~m}^{3}}{0,5 \mathrm{~m}}=0,4 \mathrm{~m}$

Ruang Reaktor :

Panjang $=0,4 \mathrm{~m}$

Lebar $\quad=1 \mathrm{~m}$

Tinggi $=0,5 \mathrm{~m}$

- Bak Pengendap Akhir

Dimensi bak pengendap

$$
\begin{aligned}
V & =Q \times t d \\
& =1,44 \mathrm{~m}^{3} / \text { hari } \times \frac{3}{24} \text { jam } \\
& =0,18 \mathrm{~m}^{3}
\end{aligned}
$$

Tinggi bak direncanakan 0,5 $\mathrm{m}$ maka luas bak pengendap

$$
\begin{aligned}
A & =\frac{V}{h} \\
& =\frac{0,18 \mathrm{~m}^{3}}{0,5 \mathrm{~m}} \\
& =0,36 \mathrm{~m}^{3}
\end{aligned}
$$

Jika lebar bak pengendap direncanakan $1 \mathrm{~m}$ maka panjang bak pengendap adalah $\mathrm{L}=\frac{\mathrm{A}}{l}$

$=\frac{0,36 \mathrm{~m}^{3}}{1 \mathrm{~m}}$

$=0,36 \mathrm{~m}^{3}=4 \mathrm{~m}^{3}$

Freeboard $=0,1 \mathrm{~m}$

Volume efektif $\quad=p \times \mid \times h$

$$
\begin{aligned}
& =0,4 \mathrm{~m} \times 1 \mathrm{~m} \times 0,5 \mathrm{~m} \\
& =0,2 \mathrm{~m}^{3}
\end{aligned}
$$


Tabel 2 Karakteristik Air Limbah Pasar Flamboyan

\begin{tabular}{|l|l|l|l|l|}
\hline \multicolumn{1}{|c|}{ Unit Pengolahan } & \multicolumn{1}{c|}{$\mathrm{P}(\mathrm{m})$} & \multicolumn{1}{c|}{$\mathrm{L}(\mathrm{m})$} & \multicolumn{1}{c|}{$\mathrm{T}(\mathrm{m})$} & \multicolumn{1}{c|}{ Efisiensi } \\
\hline Bar Screen & $0,5(\mathrm{~m})$ & $1(\mathrm{~m})$ & $1(\mathrm{~m})$ & \\
\hline Ekualisasi & $0,5(\mathrm{~m})$ & $1(\mathrm{~m})$ & $0,5(\mathrm{~m})$ & $\begin{array}{l}\text { TSS 60\% } \\
\text { BOD 40\% }\end{array}$ \\
\hline Pengendap Pertama & $0,4(\mathrm{~m})$ & $1(\mathrm{~m})$ & $0,5(\mathrm{~m})$ & $\begin{array}{l}\text { TSS 60\% } \\
\text { BOD 40\% }\end{array}$ \\
\hline Biofilter Anaerob & $1(\mathrm{~m})$ & $1(\mathrm{~m})$ & $0,5(\mathrm{~m})$ & $\begin{array}{l}\text { TSS 60\% } \\
\text { BOD 80\% }\end{array}$ \\
\hline Biofilter Aerob & $0,4(\mathrm{~m})$ & $1(\mathrm{~m})$ & $0,5(\mathrm{~m})$ & $\begin{array}{l}\text { TSS 50\% } \\
\text { BOD 60\% }\end{array}$ \\
\hline Bak Pengendap Akhir & $0,4(\mathrm{~m})$ & $1(\mathrm{~m})$ & $0,5(\mathrm{~m})$ & $\begin{array}{l}\text { TSS 50\% } \\
\text { BOD 50\% }\end{array}$ \\
\hline
\end{tabular}

Tabel 3 Rencana Anggaran Biaya

\begin{tabular}{|c|c|c|}
\hline No & UraianPekerjaan & Jumlah (Rp) \\
\hline 1 & Pekerjaan Pendahuluan & 610.000 \\
\hline 2 & Pekerjaan IPAL Pasar & 19.440 .000 \\
\hline 3 & Keperluan Bahan dan Harga & 4.455 .000 \\
\hline \multicolumn{3}{|r|}{ Jumlah 24.505 .000} \\
\hline \multicolumn{3}{|r|}{ PPN $10 \% 2.450 .500$} \\
\hline \multicolumn{3}{|r|}{ TOTAL 26.955.500 } \\
\hline \multicolumn{3}{|c|}{$\begin{array}{c}\text { Terbilang : Dua Puluh Enam Juta Sembilan Ratus Lima Puluh Lima Ribu Lima Ratus } \\
\text { Rupiah }\end{array}$} \\
\hline
\end{tabular}

\section{KESIMPULAN DAN SARAN}

A. KESIMPULAN

1. Instalasi Pengolahan Air Limbah Pasar Anggrek ini memiliki 6 kompartemen yaitu Bar Screen yang memiliki volume $0,2 \mathrm{~m}^{3} /$ hari, bak ekualisasi memiliki volume $0,25 \mathrm{~m}^{3} /$ hari, bak pengendap pertama memiliki volume $0,2 \mathrm{~m}^{3} /$ hari, biofilter anaerob memiliki volume $0,5 \mathrm{~m}^{3} /$ hari, biofilter aerob memiliki volume 0,06 $\mathrm{m}^{3} /$ hari, dan bak pengendap akhir memiliki volume $0,2 \mathrm{~m}^{3} /$ hari.

2. Anggaran biaya yang diperlukan untuk pelaksanaan perancangan Instalasi Pengolahan Air Limbah (IPAL) ini adalah sebesar Rp. 26.955.500,00,- (Dua Puluh Enam Juta Sembilan Ratus Lima Puluh Lima Ribu Lima Ratus Rupiah).

\section{B. SARAN}

1. Penelitian ini dapat dilanjutkan dengan menambahkan pengolahan terhadap lumpur.

2. Dapat dilakukan pengkajian dan perencanaan untuk saluran pipa dari kios hingga ke badan air penerima.

3. Perlunya pengkajian secara berkala untuk mengetahui kinerja dari pengolahan IPAL

4. Perlu adanya operator penanggung jawab untuk mengawasi kinerja IPAL 


\section{UCAPAN TERIMAKASIH}

Dengan selesainya perancangan ini saya mengucapkan terima kasih yang sebesarbesarnya kepada Allah Swt, kedua orang tua, kedua dosen pembimbing yaitu Bapak Winardi Yusuf, ST., MT dan Ibu Isna Apriani, ST, M.SI serta kepada teman-teman Teknik Lingkungan 2009 dan semua orang yang telah berperan dalam membantu penelitian yang tidak dapat di ucapkan satu persatu. Harapan saya penelitian ini dapat bermanfaat bagi semua dan dapat dipergunakan sebagaimana mestinya.

\section{DAFTAR PUSTAKA}

Keputusan Menteri Negara Lingkungan Hidup No.112 Tahun 2003 Tentang Baku Mutu Limbah Domestik.

Mubarok, Ahmad. 2008. Desain Instalasi Pengolahan Limbah Cair Sentra Industri Tahu Dukuh Kemranggen Kabupaten Tegal. Universitas Dipenogoro. Semarang.

Soeparman. Suparmin. 2006. Pembuangan Tinja dan Air Limbah Cair. Jakarta: Buku Kedokteran (EGC).

Peraturan Gubernur Provinsi DKI Jakarta No.112 Tahun 2005 Tentang Pengelolaan Air Limbah Domestik Di Provinsi Daerah Khusus Ibukota Jakarta. 